\title{
Invisibilidades na Avaliação Nacional da Alfabetização (ANA): os alunos com deficiência e o trabalho docente
}

\author{
Kamila Lockmann* \\ Roseli Belmonte Machado**
}

\section{Resumo}

Vivemos, na atualidade, um movimento de proliferação das avaliações em larga escala. Tal movimento convive, paradoxalmente, com a constituição da inclusão como imperativo contemporâneo. Discursos sobre o respeito à diferença chocam-se com as mediçóes globais que prometem aferir a qualidade da Educação. Diante disso, questiona-se: o que os números são capazes de medir? $\mathrm{O}$ que escapa às avaliaçôes em larga escala? Para responder tal questionamento a presente pesquisa analisou documentos oficiais que legislam sobre a Avaliação Nacional da Alfabetização e sobre os indicadores sociais; também realizou entrevistas com professores e diretores de escolas públicas localizadas em sete municípios do Rio Grande do Sul. A partir da coleta de dados argumenta-se, na esteira dos Estudos Foucaultianos, que as avaliaçóes em larga escala produzem uma espécie de semelhança imaginada, uma vez que, ao considerar algumas variáveis, deixando outras tantas de fora, estabelece invisibilidades, tanto dos alunos com deficiência, quanto do trabalho docente.

Palavras-chave: Avaliação em larga escala; Inclusão escolar; Invisibilidades.

* Professora doutora da Universidade Federal do Rio Grande (FURG), Rio grande, Rio Grande do Sul, Brasil.

** Professora da Universidade Federal do Rio Grande do Sul (UFRGS), Porto Alegre, Rio Grande do Sul, Brasil. 


\section{Invisibilities in the National Literacy Assessment (ANA): students with disabilities and teaching}

\section{Abstract}

Today we are experiencing a proliferation of large scale evaluations. This movement coexists with the constitution of inclusion as a contemporary imperative. Discourses about respecting difference are in conflict with the global measurements that promise to verify the quality of Education. So we asked: what can numbers measure? What escapes large-scale evaluations? To answer this question, the present study analyzed official documents that legislate on the National Literacy Assessment and on social indicators; also conducted interviews with teachers and principals of public schools located in seven cities of Rio Grande do Sul. With data collection, we argued from the perspective of the Foucaultian Studies that large-scale evaluations produce a kind of imagined similarity, when considering some variables, leave many out and establish invisibilities of students with disabilities and teaching work.

Keywords: Evaluation in large scale; School inclusion; Invisibilities.

\section{Invisibilidades en la Evaluación Nacional de la Alfabetización (ANA): los alumnos con discapacidad y el trabajo docente}

\section{Resumen}

Actualmente vivimos un movimiento de proliferación de las evaluaciones a gran escala. Este movimiento convive con la constitución de la inclusión como imperativo contemporáneo. Los discursos sobre el respeto a la diferencia están en conflicto con las mediciones globales que prometen verificar la calidad de la educación. Así nos pregunta: ¿qué pueden medir los números? ¿Qué escapa a las evaluaciones a gran escala? Para responder tal cuestionamiento la presente investigación analizó documentos oficiales que definen sobre la Evaluación Nacional de la Alfabetización y sobre los indicadores sociales; también realizó entrevistas con profesores y directores de escuelas públicas ubicadas en siete ciudades de Rio Grande do Sul. Con la recolección de datos argumentamos, en la perspectiva de los Estudios Foucaultianos, que las evaluaciones a gran escala producen una especie de semejanza imaginada, ya que, al considerar algunas variables, deja muchas de afuera y establece invisibilidades de los alumnos con discapacidad y del trabajo docente.

Palabras clave: Evaluación en larga escala; Inclusión escolar; Invisibilidades.

Iniciando a conversa...

Nesse delírio avaliatório agonístico ao qual submetemos os outros e ao qual nós mesmos nos submetemos, reduzem-se a quase nada os nossos próprios espaços de liberdade. (VEIGA-NETO, 2012, p. 3).

Revista Educação Especial | v. 31 | n. 63 | p. 879-892 | out./dez. 2018

Santa Maria

Disponível em: <https://periodicos.ufsm.br/educacaoespecial> 
Ao discutir as avaliaçóes em larga escala, escolhemos abrir nossa discussão com as palavras de Veiga-Neto. Concordamos com o autor quando destaca que vivemos, na atualidade, um delírio avaliatório agonístico, onde podemos perceber a invasão de práticas avaliatórias por toda a parte. $\mathrm{Na}$ recente história brasileira, é possível que não tenhamos vivenciado um momento com tamanha proliferação de avaliações em larga escala, direcionadas para as mais diversas etapas da Educação Básica e Superior, assim como para medir o desempenho de diferentes sujeitos escolares: alunos, professores, gestores, secretários de educação, entre outros. Um breve olhar nos mostra uma interminável lista: Provinha Brasil, Avaliação Nacional do Rendimento Escolar (Anresc, também conhecida como Prova Brasil), Avaliação Nacional da Educação Básica (Aneb), Avaliação Nacional de Alfabetização (ANA), Exame Nacional para Certificação de Competências de Jovens e Adultos (Enceja), Prova Nacional Docente, Avaliação Nacional da Educação Infantil (Anei), Exame Nacional do Ensino Médio (ENEM), Exame Nacional de Desempenho dos Estudantes (ENADE). Avaliaçóes que, ao circularem nos dias de hoje, incidem efeitos, não só sobre a escola e o currículo, mas também sobre as formas de ser e de viver a docência na Contemporaneidade.

Ao nos sentirmos provocadas por esse delirio avaliatório agonístico (VEIGANETO, 2012) passamos a investigar a forma atual de funcionamento de tais políticas avaliativas e as articulaçóes ou paradoxos que elas estabelecem com as políticas de inclusão contemporâneas. $\mathrm{Na}$ articulação/tensão entre as políticas de inclusão e as políticas de avaliação em larga escala, fomos mobilizadas pelos seguintes questionamentos: o que os números são capazes de medir? Que movimentos se percebe nas políticas de avaliação no intuito de contemplar as diferenças, sejam elas locais, regionais ou individuais? E talvez o mais importante: o que escapa às avaliaçóes em larga escala?

Pautadas por tais perguntas, organizamos a pesquisa a partir de duas etapas metodológicas: 1) análise documental sobre as leis e documentos que regulamentam a Avaliação Nacional de Alfabetização (ANA) e sobre os indicadores sociais, tais como: Indicador de nível socioeconômico - Inse, Indicador de Adequação da formação docente; Indicador de Esforço Docente; Indicador de Regularidade Docente; Indicador de Complexidade de Gestão; 2) entrevistas com professores e diretores de duas escolas que atendem ao maior número de alunos de inclusão em cada um dos sete municípios gaúchos selecionados para a pesquisa.

\section{Empreendimentos teórico-metodológicos}

Entendendo a implicação sempre presente entre metodologia e teorização, pensamos que, ao apresentar os caminhos trilhados por qualquer investigação, é igualmente importante apontar os pressupostos teóricos que a sustentam. Esse é o exercício que realizamos nesta seçáo.

A pesquisa, como anunciado brevemente na apresentação deste texto, dividese em dois momentos. Primeiramente, realizou-se uma análise documental de leis e regulamentos que legislam sobre a ANA e alguns indicadores sociais.

É importante ressaltar que a escolha da ANA se deu porque ela pode ser compreendida como um primeiro movimento produzido nas avaliaçóes em larga escala, 
uma vez que é a primeira forma de avaliação que cogita a possibilidade não só de elaborar instrumentos adaptados, mas também de discutir a construção de matrizes específicas considerando os alunos incluídos. Por esse motivo, a presente pesquisa tem como foco essa forma de avaliação, e, o primeiro movimento constitui-se em compreender os documentos e leis que a regulamentam. Além dos documentos que regulamentam a própria ANA, analisaram-se também algumas notas técnicas que apresentam o funcionamento de determinados indicadores sociais. Para este artigo focalizaremos apenas em um deles: Indicador de Esforço Docente.

A segunda etapa investigativa consiste em analisar as narrativas de diretores e professoras que atuam no Ciclo de Alfabetização de escolas municipais localizadas em sete municípios do Rio Grande do Sul. Em cada município pesquisado foram selecionadas duas escolas com o maior número de alunos incluídos. Tal critério foi selecionado, pois se considerou que em contextos de inclusão poder-se-ia analisar com mais detalhamento as tensóes e os paradoxos produzidos em meio ao funcionamento dessas políticas.

A partir do material analisado percebeu-se que o jogo das políticas de inclusão e de avaliação em larga escala entra em funcionamento na atualidade baseado em, pelo menos, dois grandes imperativos: o imperativo da inclusão (LOPES et. al., 2010) e o imperativo dos números (TRAVERSINI, 2012). O imperativo da inclusão aqui é tomado como algo que se impóem como verdade, que constrange, é inquestionável. As autoras destacam que a inclusão como um imperativo de Estado pode ser vista "como um princípio que demanda açôes do Estado sobre a população que quer governar. Mobilidade, acessibilidade e, por último, equidade foram constituídos como elementos fundamentais para que a inclusão universal se instituísse como uma forma de vida" (LOPES et. al., 2010, p. 22). Já no caso do imperativo dos números, Traversini (2012, p.2) destaca que as estatísticas escolares, "em especial as avaliaçóes de larga escala, possuem um caráter moral que mobiliza sua aceitação, têm força de verdade, adquirem caráter de validade e inquestionabilidade e tornam-se imperativos nas políticas educacionais e curriculares da atualidade".

É na conjugação do imperativo da inclusão e do imperativo dos números que as políticas de inclusão e as avaliaçôes em larga escala atuam. Num primeiro momento eles podem parecer contraditórios, contudo, temos visto que, cada vez mais, as políticas se alimentam. De acordo com o que temos analisado, nota-se que vivemos, na atualidade, um movimento de proliferação das avaliaçóes em larga escala, pautado num imperativo dos números. Tal movimento convive, paradoxalmente, com a constituição da inclusão como imperativo contemporâneo, o qual se baseia em discursos sobre o respeito à diferença que parecem se chocar com as mediçóes globais que prometem aferir a qualidade da Educação. Assim, parece impossível, num primeiro momento, articular uma política de avaliação externa em larga escala com as diferenças individuais de sujeitos concretos. Porém, contemplar todos os sujeitos e incluí-los na lógica performativa faz parte do jogo de um Estado neoliberal, onde impera a regra máxima da náo exclusão. Sobre isso, Foucault (2008, p. 277-278) destaca que “[...] cabe à regra do jogo imposta pelo Estado fazer que ninguém seja excluído desse jogo”. 
Com as palavras de Foucault (2008), podemos perceber que a regra geral que mobiliza o Estado neoliberal é a regra da não exclusão. Assegurar a participação de todos. Garantir o acesso de todos. Não permitir que ninguém seja excluído ou se mantenha fora do jogo. Esses princípios são mobilizadores, também, das políticas avaliativas contemporâneas, e, talvez por isso, estas busquem se articular às políticas inclusivas operacionalizadas no interior de uma racionalidade neoliberal. Essa articulação entre diversas políticas pode ser relacionada ao que Machado (2016), nomeia e descreve como um movimento de inclusão como rede, algo que "se dá por conjunturas múltiplas, cambiantes, e não hierárquicas" [...] uma rede que é "múltipla, heterogênea, e espalha-se por diversos lugares, atingindo diferentes sujeitos" (MACHADO, 2016, p. 124). Para a autora o movimento de inclusão como rede é o agenciamento de diferentes políticas, órgãos, Ministérios e sujeitos que responsabiliza a todos pela inclusão. Nesse sentido, mesmo que algumas políticas pareçam distantes e até mesmo opostas, veem-se suas articulaçóes em prol do imperativo inclusivo.

\section{Sobre a díade inclusão-avaliação em larga escala}

A aproximação entre as políticas de avaliação em larga escala às políticas de inclusão pode ser visualizada por, pelo menos, dois eixos, que chamamos aqui de Protocolos de Inclusão e Indicadores de Contexto. O primeiro eixo refere-se a forma como tais avaliaçóes, em especial a ANA, pretende incluir todos os sujeitos, promovendo não só adaptaçóes nas provas e nas suas formas de aplicação, mas também por meio da discussão sobre matrizes específicas para os sujeitos da inclusão. O segundo eixo é desenvolvido pela criação e proliferação dos indicadores sociais, os quais relacionam os resultados obtidos nas provas de desempenho a aspectos sociais, educacionais, de formação e gestão escolar, contextualizando-os. São esses dois movimentos que constituem as unidades analíticas deste texto. Neles perceberemos o funcionamento da díade inclusão-avaliação em larga escala e como por meio dela percebemos movimentos de in/exclusão que produzem invisibilidades tanto dos sujeitos da inclusão, quanto do trabalho docente.

\section{Protocolos de Inclusão}

O Inep prevê na ANA o desenvolvimento de açóes com vistas ao atendimento específico para alunos com necessidades educativas especiais. Nesse sentido, vem discutindo o desenvolvimento de estratégias distintas, tais como construção de matrizes especificas e elaboração de instrumentos adaptados (BRASIL, 2013, p. 7).

Art. $4^{\circ}$ A ANA 2014 será realizada no período de 17 a 28 de novembro de 2014, em todos os Estados e no Distrito Federal. $\$ 1 O$ Inep disponibilizará provas ampliadas (em fonte 18) e superampliadas (em fonte 24) para os estudantes com baixa visão, de acordo com os dados fornecidos pelas unidades escolares no Censo Escolar 2014. \$2 Será assegurado tempo adicional aos estudantes com deficiência, transtornos globais ou específicos do desenvolvimento, síndromes ou outras necessidades especiais. 
Art. 50 Cada unidade escolar poderá fazer uso de seus recursos de Atendimento Educacional Especializado - AEE, para garantir melhores condiçôes de atendimento, acessibilidade e participação nas avaliaçóes aos estudantes com deficiência, transtornos globais ou específicos do desenvolvimento, síndromes ou outras necessidades especiais (BRASIL, 2014, p. 26).

Os excertos evidenciam o movimento de aproximação entre políticas aparentemente contraditórias: politicas de avaliação em larga escala e políticas de inclusão. Trata-se da operacionalização da regra máxima do jogo neoliberal: a regra da não exclusão. Ninguém pode ficar fora da lógica performativa e todos precisam ser contabilizados nos índices que medem os desempenhos dos alunos em alfabetização. Isso inclui, obviamente, os alunos com deficiência. É nesse ponto que podemos perceber o movimento produzido pelas avaliaçóes em larga escala, aqui em especial pela ANA, em direção às políticas de inclusão.

Porém, obviamente esse movimento não ocorre sem tensões. Se por um lado tais políticas não se colocam em oposição, tampouco suas articulações são neutras e inocentes. Para explicar as tensóes existentes nessa relação entre as políticas de avaliação em larga escala e as políticas de inclusão, Hattge (2013) trabalha com a ideia de paradoxo. Ela diz que a inclusão se constitui no paradoxo da performatividade, lembrando que isso não significa o mesmo que contradição ou oposição. A autora explica sua escolha da palavra paradoxo considerando sua constituição semântica. Enquanto a palavra contradição apresenta o prefixo contra-, que dá a ideia de oposição, paradoxo apresenta o prefixo para-, que traz em si a ideia de proximidade, de estar junto a. Trata-se, entâo, segundo Hattge (2013, p. 146), de a inclusão estar "junto à" performatividade, pois sem a inclusão a performatividade não se efetiva. É justamente aqui que o paradoxo entre inclusão e performatividade entra em funcionamento. Se, por um lado, exige-se a participaçáo de todos os sujeitos nos processos de avaliação, ou seja, todos precisam estar incluídos, por outro, é essa mesma inclusão que ameaça os resultados produzidos pelas avaliaçóes, ou seja, ameaça a própria performatividade.

Eis o paradoxo que a díade inclusão-avaliação em larga escala coloca em funcionamento ao conjugar padronização e diferenciação, medida comum e individualidades diferenciais. É na produção desse jogo paradoxal que podemos visualizar as invisibilidades aí produzidas. O que escapa dessas avaliaçôes? Mesmo considerando seus movimentos em prol da inclusão de todos os sujeitos, o que fica de fora? O que não é visualizado ou operacionalizado tal como idealizado pela política?

$\mathrm{Na}$ busca por compreender tais questóes foram realizadas entrevistas com professores e diretores de duas escolas que atendem ao maior número de alunos de inclusão em cada um dos municípios gaúchos selecionados: Porto Alegre, São Leopoldo, Lajeado, Rio Grande, Pelotas, Alegrete e Novo Hamburgo. A seguir são trazidos dois excertos dessas entrevistas que nos fazem pensar sobre o modo como a ANA, embora indique a elaboração de instrumentos adaptados, também cria invisibilidades.

Participam, participam [da ANA] porque como eles estão incluídos em uma escola regular eles têm que participar de tudo que se faz né? E essa prova não é adaptada, não é com currículo adaptado, 
nem nada. Alguns deles têm monitores e os monitores ajudam. Eles têm direito a mais tempo, têm direito a sair de sala de aula nas provas quando são dadas, são dadas folha a folha pra eles né? Pra eles não se perderem, porque eles têm uma dificuldade maior. Mas, eles participam também e por isso baixa tanto o índice né, porque hoje a gente tem vinte e seis alunos incluídos dentro da escola, em diversas séries, sendo que o terceiro ano é o que mais tem em função de que, quando barra é no terceiro ano, então a gente tem muitos alunos no terceiro ano. (Diretora A, Município A, 2016).

Eu só gostaria que, como a gente trabalha com inclusão né, e a gente tem que fazer determinadas coisas em relação a isso, eu gostaria que a ANA também fizesse, entende? Que ela também fosse preparada pra isso. Por exemplo, eu tenho um aluno autista, então vai vir uma prova específica pra esse aluno autista, com o currículo adaptado. Eu gostaria que a coisa fosse um pouquinho diferente, entende? Porque a gente tem que trabalhar as especificidades do aluno, a gente tem que tratar cada um como um ser diferente, mas aí vem uma prova dessas que né, bota todo mundo no mesmo patamar. A minha crítica é essa e já me mandaram ficar quieta né. (Diretora B, Munícipio A, 2016).

Notam-se, no breve relato das diretoras, algumas das invisibilidades geradas pela ANA, mesmo com a proposta de uma política que pretende contemplá-los. Os alunos com deficiência são convocados a realizar as provas e são propostos alguns materiais adaptados e formas de execução dessas provas - protocolos de inclusão -, contudo, isso não contempla as singularidades desses sujeitos. Os relatos nos mostram que para os alunos com deficiência as escolas têm trabalhado com currículos adaptados e individuais para cada sujeito, conforme orienta a legislação educacional, mas a ANA não contempla esses currículos. Além disso, os índices da escola, após a aplicação da ANA, não mostram essas especificidades - elas ficam invisíveis - e a escola acaba tendo um índice baixo preocupando o corpo docente. Não obstante a essa situação, a ANA também torna invisível o trabalho docente. O currículo adaptado a cada um, as atividades realizadas pelos professores e o atendimento que a escola oferece a esses sujeitos não aparece na avaliação. Nos relatos acima também vemos uma relação de contradição, pois, enquanto os professores elaboram e realizam um currículo e avaliaçóes diferenciadas para os alunos com deficiência, a ANA não considera tais situaçôes. Há um apagamento do trabalho docente e da escola.

Percebe-se uma relação de in/exclusão nessa situação. Todos os alunos são convocados pela ANA a realizarem a avaliação e, para os alunos com deficiência é pensada a possibilidade de serem elaborados instrumentos adaptados, além de se discutir a construção de matrizes específicas. Ou seja, estão sendo pensadas estratégias para que todos sejam alcançados e incluídos por essa prática avaliativa. Todavia, na realização dessa avaliação, o que vemos são situaçôes que excluem esses sujeitos, os tornam invisíveis ou mesmo indesejados dentro do jogo, pois diminuem os índices escolares. Assim, o que vemos se estabelecer é uma relação de in/exclusão.

\section{Indicadores de Contexto}

$\mathrm{O}$ segundo movimento discutido neste trabalho trata de contextualizar os resultados obtidos por meio das provas de desempenho. No caso específico da ANA, analisado nesta pesquisa, não se trata apenas de produzir e divulgar dados estatísticos 
sobre o resultado do desempenho de alunos e escolas, comparando-os indiscriminadamente. A produção desses dados estatísticos acopla-se aqui com informaçóes obtidas sobre o contexto socioeconômico das famílias, sobre a infraestrutura das escolas, sobre as condiçóes de trabalho dos professores, sobre a formação docente e a gestâo escolar, ou seja, sobre as condiçóes intra e extraescolares que incidem sobre o processo de ensino e aprendizagem. Para que isso seja possível, o Inep disponibilizou o Perfil de "Escolas Similares", o qual trata de sintetizar os resultados obtidos pelas escolas na Avaliação Nacional da Alfabetização (ANA) e Avaliação Nacional do Rendimento Escolar (Provinha Brasil), considerando o contexto socioeconômico em que se encontram inseridas. A elaboração desses perfis é realizada a partir da análise de três critérios sendo eles: Microrregião geográfica, cujos resultados darão origem ao "Grupo Principal"; Localização da escola, onde subdivide-se em Grupo rural e Grupo urbano; e por fim, o indicador do nível socioeconômico.

[...] optou-se por oferecer a cada escola, que participou da Avaliaçáo Nacional da Alfabetização ANA) e/ou da Avaliação Nacional do Rendimento Escolar (Anresc, também denominada Prova Brasil), um Perfil de escola que servisse de referência para a análise de seus resultados, mas que considerasse o contexto sócioespacial em que está inserida e as características sóciodemográficas dos alunos atendido (BRASIL, 2014,p. 1).

Após a criação desse perfil, a escola recebe o nome de "Sua escola" e cria-se um grupo com outras 16 escolas, semelhantes dentro desses critérios, para análises dos resultados obtidos nos instrumentos avaliativos. São selecionados 8 escolas com nota superior a "Sua escola" e 8 escolas com resultados inferiores. Com isso, a escola pode comparar os resultados obtidos com escolas com perfis equivalentes aos seus. Essa nova forma de atuação das políticas de avaliaçáo em larga escala pode ser compreendida a partir do que Lockmann (2013) denominou de semelhança imaginada. A autora baseia-se nas ideias de Foucault e Senra para construir tal noção nos mostrando que para encontrar semelhança entre as coisas, é preciso ter sempre presente uma dose de imaginação. Com isso, Lockmann (2013) está querendo mostrar que a semelhança apontada entre essas escolas, ditas similares, é construída a partir da reunião de determinados aspectos que podem lhe conferir similitudes, porém não podemos esquecer que outros tantos aspectos são deixados de fora, e talvez, justamente eles, poderiam denunciar a ampla diferença presente entre as escolas comparadas e apresentadas como similares.

Foucault (2007, p. 93) destaca que "[...] uma relação de ordem não pode ser estabelecida entre duas coisas, senão quando sua semelhança tenha sido ao menos a ocasiāo de compará-las". O autor salienta, ainda, que "sem imaginação não haveria semelhança entre as coisas. [...] É preciso que haja, nas coisas representadas, o murmúrio insistente da semelhança; é preciso que haja, na representação, o recôndito sempre possível da imaginação" (FOUCAULT, 2007, p. 95).

O funcionamento da noção de semelhança imaginada pode ser visualizado na análise de alguns indicadores sociais que também compóe o material empírico da investigaçáo. Focalizaremos a análise no indicador de esforço docente, o qual preten- 
de mensurar "o esforço empreendido pelos docentes da educação básica brasileira no exercício de sua profissão através de um conjunto de variáveis tomadas como definidoras do esforço do trabalho docente". (NOTA TÉCNICA No 039/2014, p.1). As variáveis apresentadas pela nota técnica que apresenta tal indicador são: (1) número de escolas em que atua; (2) número de turnos de trabalho; (3) número de alunos atendidos e (4) número de etapas nas quais leciona. A partir de tais variáveis a nota apresenta a uma tabela que descreve os níveis de esforço docente. $\mathrm{Na}$ figura abaixo poderemos ver essa tabela.

Figura 1 - Tabela presente na Nota Técnica nº 039/2014

\begin{tabular}{|l|l|}
\hline Níveis & Discrição \\
\hline Nível 1 & Docente que tem até 25 alunos e atua em um único turno, escola e etapa. \\
\hline Nível 2 & $\begin{array}{l}\text { Docente que tem entre 25 e } 150 \text { alunos e atua em um único turno, escola e } \\
\text { etapa }\end{array}$ \\
\hline Nível 3 & $\begin{array}{l}\text { Docente que tem entre 25 e } 300 \text { alunos e atua em um ou dois turnos em uma } \\
\text { única escola e etapa. }\end{array}$ \\
\hline Nível 4 & $\begin{array}{l}\text { Docente que tem entre } 50 \text { e } 400 \text { alunos e atua em dois turnos, em uma ou } \\
\text { duas escolas e em duas etapas. }\end{array}$ \\
\hline Nível 5 & $\begin{array}{l}\text { Docente que tem mais de } 300 \text { alunos e atua nos três turnos, em duas ou três } \\
\text { escolas e em duas etapas ou três etapas }\end{array}$ \\
\hline Nível 6 & $\begin{array}{l}\text { Docente que tem mais de } 400 \text { alunos e atua nos três turnos, em duas três } \\
\text { escolas e em duas etapas ou três etapas. }\end{array}$ \\
\hline
\end{tabular}

Fontes: Retirado de: BRASIL, Nota Técnica 039/2014.

Se por um lado podemos perceber uma espécie de contextualização das condiçóes de trabalho do professorado brasileiro; o que de fato pode influenciar nos índices obtidos pelos alunos nas provas de desempenho, por outro lado, podemos colocar em xeque as próprias variáveis construídas como parâmetro para mensurar o esforço docente e mostrar que muitas outras variáveis são desconsideradas e invisibilizadas nesse indicador. Se anteriormente enfatizamos que os sujeitos com deficiência são invisibilizados nas avaliaçóes em larga escala, inclusive naquelas que os pretendem contemplar, aqui destacamos a invisibilidade de aspectos do trabalho docente.

Segundo as informaçôes apresentadas na nota técnica No 039/2014 os professores que atuam nos anos finais do Ensino Fundamental ou no Ensino Médio dispendem um esforço docente maior no exercício da sua função, do que aqueles que atuam nos anos iniciais do Ensino Fundamental. Na figura a seguir trazemos outra tabela que mostra que 39,5\% dos professores que atuam nos anos finais do Ensino Fundamental apresentam o nível 4 de esforço docente, enquanto que no Ensino Médio esse mesmo nível de esforço docente sobe para 43,7\%. Tal nível, mostrado na figura anterior, refere-se a professores que atendem entre 50 e 400 alunos, atuando em duas etapas, em dois turnos, podendo ser distribuídos em uma ou duas escolas. A figura a seguir materializa a distribuição dos docentes de cada etapa da educação básica de acordo com o nível de esforço. 
Figura 2 - Tabela de docentes de acordo com o nível de esforço

\begin{tabular}{|l|c|c|c|c|c|c|}
\hline & 2009 & 2010 & 2011 & 2012 & 2013 & 2014 \\
\hline Educação Infantil & $1,11 \%$ & $1,03 \%$ & $0,90 \%$ & $0,81 \%$ & $0,79 \%$ & $0,78 \%$ \\
\hline EF-Anos Iniciais & $2,10 \%$ & $2,35 \%$ & $2,57 \%$ & $2,71 \%$ & $2,75 \%$ & $2,83 \%$ \\
\hline EF-Anos Finais & $0,72 \%$ & $0,90 \%$ & $1,07 \%$ & $1,29 \%$ & $1,43 \%$ & $1,63 \%$ \\
\hline Ensino Médio & $0,27 \%$ & $0,34 \%$ & $0,41 \%$ & $0,52 \%$ & $0,58 \%$ & $0,70 \%$ \\
\hline Educaçăo Profissional & $0,21 \%$ & $0,19 \%$ & $0,22 \%$ & $0,23 \%$ & $0,21 \%$ & $0,24 \%$ \\
\hline EJA & $1,59 \%$ & $1,86 \%$ & $2,07 \%$ & $2,69 \%$ & $2,88 \%$ & $3,12 \%$ \\
\hline
\end{tabular}

Fontes: Retirado de: BRASIL, Nota Técnica 039/2014.

A ideia, bastante simplificada, de que os professores que atuam nos anos iniciais dispendem um esforço docente menor do que aqueles que atendem alunos do Ensino Médio pode ser facialmente questionada. Será mesmo que podemos afirmar, por exemplo, que um professor de uma escola do campo, que atua em um único turno, sendo professor, diretor, secretário e professor de apenas 6 alunos em uma turma multiseriada, dispende menos esforço para atender seus alunos do que um professor do primeiro ano do Ensino Médio que trabalha dois turnos e atende 53 alunos? Podemos afirmar que um professor que atende a 25 alunos no terceiro ano do Ensino Fundamental, dispende menos esforço docente do que um professor de Matemática atendendo alunos no Ensino Médio? É possível contabilizar e mensurar o esforço docente desses profissionais? Náo se trata aqui de tentar definir qual seria a etapa da Educação Básica mais complexa e que exige maior esforço docente. No lugar disso, consideramos muito mais produtivo problematizar aquilo que escapa, o que é invisibilizado num indicador como esse. Muitos aspectos do trabalho docente são invisibilizados, além de, novamente os sujeitos da inclusão serem desconsiderados por tal indicador. Vejamos a figura a seguir:

Figura 3 - Tabela com a proporção de alunos com necessidades especiais matriculados na Educação Básica ao longo dos anos

\begin{tabular}{|l|c|c|c|c|c|c|}
\hline & 2009 & 2010 & 2011 & 2012 & 2013 & 2014 \\
\hline Educação Infantil & $1,11 \%$ & $1,03 \%$ & $0,90 \%$ & $0,81 \%$ & $0,79 \%$ & $0,78 \%$ \\
\hline EF-Anos Iniciais & $2,10 \%$ & $2,35 \%$ & $2,57 \%$ & $2,71 \%$ & $2,75 \%$ & $2,83 \%$ \\
\hline EF-Anos Finais & $0,72 \%$ & $0,90 \%$ & $1,07 \%$ & $1,29 \%$ & $1,43 \%$ & $1,63 \%$ \\
\hline Ensino Médio & $0,27 \%$ & $0,34 \%$ & $0,41 \%$ & $0,52 \%$ & $0,58 \%$ & $0,70 \%$ \\
\hline Educação Profissional & $0,21 \%$ & $0,19 \%$ & $0,22 \%$ & $0,23 \%$ & $0,21 \%$ & $0,24 \%$ \\
\hline EJA & $1,59 \%$ & $1,86 \%$ & $2,07 \%$ & $2,69 \%$ & $2,88 \%$ & $3,12 \%$ \\
\hline
\end{tabular}

Fontes: Retirado de: http://www.todospelaeducacao.org.br/. 
Ao compararmos o número de alunos com deficiência ao total de estudantes matriculados em cada etapa da Educação Básica regular, vemos que a proporção no Ensino Médio é bastante inferior às encontradas nos Anos Iniciais e Finais do Ensino Fundamental. Nos Anos Iniciais do Ensino Fundamental, por exemplo, os alunos com deficiência, transtornos globais do desenvolvimento e altas habilidades ou superdotação representavam 2,83\% do total de alunos matriculados nesta etapa em 2014, enquanto no Ensino Médio, a proporção era de apenas $0,70 \%$. Isso indica que dos os alunos com essas características que entram no Ensino Fundamental, um percentual menor chega ao Ensino Médio (TPE, 2015). Somente esse dado, já mostra que uma variável importante para construir uma possível medição do esforço docente, é desconsiderada por esse indicador, qual seja: a presença de alunos de inclusão nas classes das etapas da Educação Básica. Com isso vemos que aspectos importantes do trabalho docente são silenciados pelos índices que pretendem contextualizar os resultados obtidos pelas avaliaçóes em larga escala.

Ademais, ao analisarmos o que esses indicadores pretendem mostrar, é possível notar a força de verdade que os números possuem. Essa força de verdade potencializa-se, na medida em que os cálculos estatísticos, antes genéricos e comparados indiscriminadamente entre toda e qualquer instituição, agora se articulam a informaçóes de contexto que descrevem as instituiçôes escolares como semelhantes. Ressalta-se aqui o conceito de imperativo dos números, quando, ao tratar das avaliaçóes em larga escala, constitui uma verdade que vai se articulando e sendo aceita como algo inquestionável. Com isso, não nos colocamos contra as avaliaçôes em larga escala, porém mostramos que a complexidade da vida escolar náo cabe nos números. Muitas questôes são invisibilizadas na produção desses dados e isso precisa ser problematizado, uma vez que a estatística vem assumindo um lugar de veridicção na atualidade.

\section{Considerações Finais}

No desenrolar da investigação, procuramos ressaltar três pontos principais, que, embora não tivessem sido tratados ordenadamente, estiveram presentes na problematização empreendida. Trata-se de pensar sobre o que os números são capazes de medir; refletir a propósito dos movimentos nas políticas de avaliação no intuito de contemplar as diferenças; e, sobre aquilo que escapa às avaliaçóes em larga escala.

As reflexões sobre o que os números são capazes de medir focam nosso olhar para a proliferação e a presença marcante da estatística na condução da ANA. Os dados produzidos pelo saber estatístico atravessam o universo escolar na tentativa de mostrar uma verdade sobre as escolas, as famílias, a gestão escolar, as condiçóes e o trabalho docente. Tais situaçóes são destacadas naquilo que é chamado do perfil "Sua escola”, o qual, para além de dizer uma verdade sobre o contexto escolar, também procura o comparar com um grupo de 16 outras escolas - uma semelhança imaginada. Sabe-se que a ideia atrelada a esse movimento vai ao encontro de questionar os motivos que levam uma escola a ter baixos índices nas avaliaçóes, responsabilizando os sujeitos que a constituem - principalmente professores e gestores - por esse resultado. Um insidioso movimento, pois, como destacamos no decorrer desta investigação, inúmeros aspectos ficam à margem do que esses números podem mostrar o que destacaria a diferença entre os universos escolares que foram confrontados. 
$\mathrm{Na}$ mesma esteira de pensamento, quando nos debruçamos a analisar a que se propóem os movimentos das políticas de avaliação a fim de contemplar as diferenças, principalmente de incluir nas avaliaçóes os alunos com deficiência, vemos em destaque a regra máxima do jogo neoliberal: a náo exclusão. Todos devem ser medidos, avaliados e comparados dentro do jogo performático neoliberal, todavia, ao mesmo tempo em que se incluem esses sujeitos, cria-se um paradoxo entre entra inclusão e performatividade, pois o movimento de inclusão coloca em xeque a lógica performativa. Essa questão provoca uma inquietude nas escolas, pois os protocolos de inclusão propostos pelas avaliaçóes em larga escala não contemplam as especificidades dos alunos com deficiência, não sendo capazes de mostrar suas evoluçốes, desempenhos e/ou o trabalho empreendido pela escola e pelos professores junto a esses sujeitos. Ao ter ciência de tal situação e, ao mesmo tempo, na busca por melhores índices nas avaliaçóes que garantem diversos tipos de reconhecimento à escola, os envolvidos nesse processo se colocam a questionar essas avaliaçóes que invisibilizam os processos ali desenvolvidos.

Essas situaçôes nos conduzem a considerar aquilo que escapa às avaliaçôes em larga escala, principalmente no que diz respeito aos alunos com deficiência e ao trabalho docente desenvolvido nessa relação. Nos aspectos trazidos nesta investigação observamos o trabalho docente silenciado pelos indicadores. As escolas têm procurado trabalhar com currículos adaptados considerando cada sujeito, mas as avaliaçóes em larga escala, ao trazer adaptaçóes materiais e insuficientes, não contempla cada realidade. Isso é invisibilizado nos índices, marginalizando o trabalho produzido pela escola, pelos professores, bem como os próprios alunos com deficiência. Como dissemos, uma relação de in/exclusão.

A partir desses três pontos argumentamos, na esteira de pensamento dos Estudos Foucaultianos em Educação, que as avaliaçóes em larga escala produzem uma espécie de semelhança imaginada, uma vez que, ao considerar algumas variáveis, deixando outras tantas de fora, estabelece invisibilidades, tanto dos alunos com deficiência, quanto do trabalho docente.

\section{Referências}

BRASIL. Avaliaçáo Nacional da Alfabetizaçáo (ANA): documento básico. - Brasília: Instituto Nacional de Estudos e Pesquisas Educacionais Anísio Teixeira, 2013. Disponível em: http://download.inep.gov.br/educacao_basica/saeb/2013/livreto_ANA_online.pdf Acesso em 10 de maio de 2018.

BRASIL, Portaria no 468, de 19 de setembro de 2014. INEP, 2014. Disponível em: http://portal.inep.gov.br/ web/saeb/ana. Acesso em 10 de maio de 2018.

BRASIL. Nota Técnica - Perfil de Escolas Similares. INEP, 2014. Disponível em: http://download.inep.gov. br/educacao_basica/prova_brasil_saeb/resultados/2013/nota_tecnica_perfil_de_escolas_similares.pdf Acesso em 10 de maio de 2018.

BRASIL. Nota Técnica No 039/2014 - Indicador do Esforço Docente. INEP, 2014. Disponível em: http:// download.inep.gov.br/informacoes_estatisticas/indicadores_educacionais/2014/docente_esforco/nota_tecnica_indicador_docente_esforco.pdf. Acesso em 10 de maio de 2018.

FOUCAULT, Michel. As palavras e as coisas: uma arqueologia das ciências humanas. São Paulo: Martins Fontes, 2007.

FOUCAULT, Michel. Nascimento da Biopolítica: curso no Collège de France (1978- 1979). São Paulo: Martins Fontes, 2008.

Revista Educação Especial | v. 31 | n. 63 | p. 879-892 | out./dez. 2018 
HATTGE, Morgana Domênica. Peformatividade e Inclusão no movimento todos pela educaçáo. São Leopoldo, 2013. Tese (Doutorado em Educação) — Programa de Pós-Graduaçáo em Educaçãa, Faculdade de Educação, Universidade do Vale do Rio dos Sinos -UNISINOS, São Leopoldo, 2013

LOCKMANN, Kamila. A proliferação das políticas de assistência social na educaçáo escolarizada. Tese (Doutorado em Educação), Programa de Pós-Graduação em Educaçâo da Universidade Federal do Rio Grande do Sul, Porto Alegre, RS, 2013.

LOPES, Maura Corcini et al. Inclusão e biopolítica. Caderno IHU Ideias, ano 8, n. 144, 2010.

MACHADO, Roseli Belmonte. A inclusão com rede: uma análise de práticas de professores de Educação Física na Contemporaneidade. Tese (Doutorado em Educação), Programa de Pós-Graduação em Educaçăo da Universidade Federal do Rio Grande do Sul, Porto Alegre, RS, 2016.

TRAVERSINI, Clarice Salete. Currículo e avaliação na contemporaneidade: há lugar para a diferença em tempos de imperativo dos números? In: X Colóquio sobre Questóes Curriculares / VI Colóquio Luso Brasileiro de Currículo - 4,5 e 6 de setembro de 2012. Belo Horizonte: FAE- UFMG, 2012.

VEIGA-NETO, Alfredo. Delírios avaliatórios: o currículo desvia para a direita ou um farol para o currículo. Texto apresentado no X Colóquio sobre Questóes Curriculares e VI Colóquio Luso-Brasileiro de Currículo. Belo Horizonte: UFMG, 2012. Disponível em: http://www.fe.unicamp.br/TEMPORARIOS/veiga-netocurriculos-delirios-avaliatorios.pdf

\section{Correspondência}

Kamila Lockmann - Universidade Federal do Rio Grande (FURG), Av. Itália km 8, CEP: 96203-900, Carreiros, Rio Grande, Rio Grande do Sul, Brasil.

E-mail: kamila.furg@gmail.com - robelmont@yahoo.com.br

Recebido em 13 de junho de 2018

Aprovado em 08 de setembro de 2018

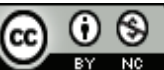

This work is licensed under a Creative Commons Attribution-NonCommercial 4.0 International (CC BY-NC 4.0) 
